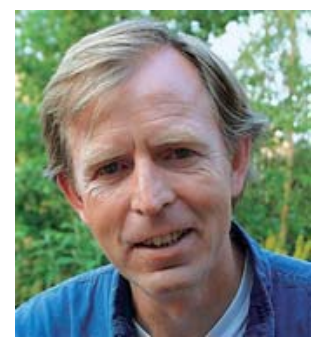

\title{
200th Anniversary of the Organon
}

For homeopaths the term Organon immediately refers to Hahnemann's classic and most fundamental treatise on homeopathy. Those that know nothing or little about homeopathy, especially if they have enjoyed a classics training, will rather think of Aristotle when hearing the term Organon. Several of Aristotle's treatises regarded as comprising his logical works have been grouped by ancient commentators together under the title Organon (“Instrument").

The term Organon for their intellectual inheritance and the adjective "classical" to their schools of thought are not the only parallels between Hahnemann and Aristotle. Just as some followers of Aristotle, like Kant, thought that Aristotle had discovered everything there was to know about logic, many of Hahnemann's followers tend to consider his Organon as a complete "instrument" that needs no further development and improvement.

The historian of logic Prantl even drew the corollary that any logician after Aristotle who said anything new was confused, stupid, or perverse. At times similar kinds of qualifications have regretfully also been used to put down homeopaths who have dared to explore beyond Hahnemann's territory.

In a letter to his publisher Hahnemann writes about his 6th Organon that it has "if possible, become perfect". Add to this his famous "Mach es nach, aber mach es genau nach", and it is clear why homeopaths may tend to follow the Organon to the letter and have great difficulty in considering homeopathy as an organic science that keeps growing and developing.

Hahnemann kept experimenting all his life. It would indicate a drastic change of character to assume that uncured cases would not have stimulated Hahnemann to further develop homeopathy after finalizing the 6th Organon, had he been given the time. Each edition of the Organon was perfect in that it expressed the best way to apply homeopathy based on the state of development of theory and practice of that moment, and with each edition there remained to be cured, uncured cases, also with the last "if possible, perfect" edition. This year we are celebrating the first edition of Hahnemann's "instrument" and we may be grateful for the fact that Hahnemann lived 88 years and had the opportunity to keep observing and learning from his cases, and to rewrite his magnum opus five times. It is our responsibility to have the courage, the open-mindedness, the curiosity and the perseverance to put into practice Hahnemann's other credo - "aude sapere" - and to create an, if possible, even more perfect 7th Organon.

More than two millennia after Aristotle it is generally accepted that his logic has had an unparalleled influence on the history of Western thought. It may be anticipated that another two thousand years from now Hahnemann's Organon will similarly have an unparalleled influence on world healthcare and that his "instrument" will be widely in vogue much earlier than that. To attain that we not only need to cherish his legacy but also have the courage to improve it.

Harry van der Zee
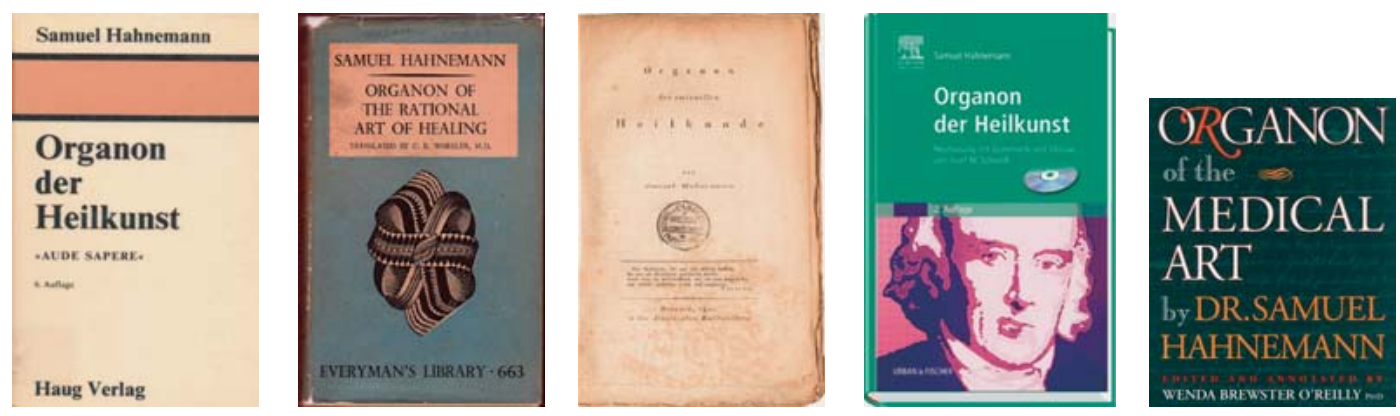